\title{
Evaluation of installation procedures of volumetric water content and matric potential probes: fundamentals for obtaining field and laboratory accordance
}

\author{
Thiago de Souza Carnavale ${ }^{1 \text { and } 2^{*}}$, Tácio Mauro Pereira de Campos $^{1}$, and Haimon Diniz Alves Lopes ${ }^{3}$ \\ ${ }^{1}$ Civil Engineering Department, Pontifical Catholic University of Rio de Janeiro (PUC-Rio) - Brazil \\ ${ }^{1}$ Civil Engineering, Centro Universitário Serra dos Órgãos (UNIFESO) - Brazil \\ ${ }^{2}$ Physics Institute, Rio de Janeiro State University (UERJ) - Brazil
}

\begin{abstract}
The current paper aims to analyze the influence of installation procedures when it comes to the accordance of the Soil Water Retention Curve and field monitoring data. The method comprises testing three different installation procedures: with driving the rod into the soil; with the application of mud inside the auger hole; and with a hardened steel gauge. Further, is evaluated the influence of the variation of Bulk density on volumetric water content values by using the Proctor and a double ring hydraulic equipment. To analyze the soil-rod coupling, a microtomography imaging routine was performed. The results point out that the probe's data are connected to the Bulk density of the material, producing higher volumetric water content values with the increase of Bulk density. Comparing results of different installation methods with laboratory results, it is possible to conclude that driving the rod directly into the soil is the best way to install the equipment since the probe underestimates the volumetric water content data by $2,5 \%$, while the mud application by $4 \%$, and the gauge method by $5 \%$.
\end{abstract}

\section{Introduction}

The use of field monitoring is expanding with the increase of interactions between society and the environment. In this regard, real-time moisture and suction data acquisition is extremely important to support predictions and solve geoenvironmental problems.

In terms of geotechnical issues such landslides, recovery of degraded areas, and disasters management, the volumetric water content (VWC) and the matric potential (MP) determination reveal remarkable information concerning the transient features of soilweather interaction.

In this way, the soil water retention curve (SWRC) is a relevant procedure because it depicts free-draining water and air-entry values that point out the transition from the saturated zone to the residual water content of soils. Further, it is well-know that suction, in broad terms, is related to the mechanical behavior of soils by transient stress state variables (Fredlund \& Morgenstern, 1976) [1].

The procedures to measure suction and moisture content of soils are initially guided by Gardner (1937) [2], and Richards (1944) [3]. The aforementioned authors started to use the filter paper and pressure plate methods to determine the soil retention curve, which later evolved to ASTM 5298-94 (2016) [4], and ASTM C1669 (2015) [5].

In the light of field measurements, Topp (1985) [6] introduced the time domain reflectometry (TDR) as a technique to determine the volumetric water content of soils by soil electrical permittivity. His pioneer research was responsible to provide a new range of possibilities for real-time data acquisition and field monitoring.

Although the correlation between predicted and measured SWRC started almost a hundred years ago, this subject is still in progress as new practices and arrangements are emerging. Regarding this, comparisons between field and laboratory SWRC moisture and suction values have been presented by several authors (Morgan et al., 2001 [7]; Li et al., 2005 [8]; Osisnki et al., 2016 [9]), who have reported divergences among data acquired by different procedures (time domain reflectometry probes versus tensiometer versus filter paper versus pressure plate).

Bearing that in mind, this study presents an approach to reach a reliable SWRC based on field monitoring data. It comprises the use of sensors manufactured by Decagon Devices Inc., an MPS-2 probe for matric potential, and an EC-5 probe for volumetric water content data acquisition.

Hence, the current paper aims to: analyze the correlation between the soil Bulk density with VWC acquired values; evaluate different installation technics

\footnotetext{
* Corresponding author: thicarnavale@gmail.com
} 
of EC-5 probes; verify the range and accuracy of the probes; and perform a field soil water retention curve (FSWRC).

\section{Materials}

For the following tests, were used soil samples from Tinguá, Nova Iguaçu - Rio de Janeiro - Brazil. The area is located in the Pontifical Catholic University of Rio de Janeiro - Experimental Campus, under coordinates 663961E / 7500946N. By fieldwork campaigns was observed the soil sample material arises from a colluvial domain, originated by biotite-gneiss in which multiple mass transportation events removed the bedrock characteristics. The grains size, plasticity index, and the liquid limit analysis were performed using the Brazilian Standards (ABNT), NBR-7181 [10], NBR-6459 [11], NBR-7180 [12]. In complement, Specific Gravity was performed under American Standard Test Method D854-14 [13]. The results are presented in Table 1 and Table 2.

Table 1. Grain size distribution (GSD) data.

\begin{tabular}{c|c|c}
\hline \multicolumn{3}{c}{ GSD - Colluvial } \\
\hline Gravel & & 2.90 \\
\hline \multirow{4}{*}{ Sand } & Coarse & 24.60 \\
& Medium & 14.20 \\
& Fine & 7.70 \\
& Total & 46.50 \\
\hline \multirow{3}{*}{ Finer } & Silt & 10.10 \\
& Clay & 40.50 \\
& Total & 50.60 \\
\hline
\end{tabular}

Table 2. Soil properties.

\begin{tabular}{c|c}
\hline \multicolumn{2}{c}{ Colluvial soil properties } \\
\hline Specific Gravity $G_{\mathrm{s}}$ & 2.66 \\
Natural Specific Mass $\rho_{n}\left(\mathrm{~g} / \mathrm{cm}^{3}\right)$ & 1.59 \\
Dry Specific Mass $\rho_{d}\left(\mathrm{~g} / \mathrm{cm}^{3}\right)$ & 1.30 \\
\hline
\end{tabular}

\section{Methods}

\subsection{Laboratory Soil Water Retention Curve}

The filter paper method (Marinho, 2006) [14] was used to determine the soil water retention curve in the laboratory. For the procedure, the filter paper Whatman No. 42 was kept in contact with the soil sample and the setup remained covered by a plastic seal until the data acquisition was concluded. In addition, the samples were thermally protected in an expanded polystyrene box for 15 days, after which another data acquisition was performed.

The current paper did not analyze the hysteresis effects. The soil samples were wetted and dried from the natural field water content point, reaching different moisture and suction levels by two branches (moistening and drying).
In this paper, the adjustment method used was Durner (1994) [15]. This model was chosen because it is an extension of Van Genuchten's model (1985) [16] combined with Maulem's (1976) [17] conductivity prediction model. It concerns unimodal curves superimposition, which is appropriate for heterogeneous pore systems like bimodal and multimodal soils.

\subsection{Field monitoring}

For the field monitoring and its related soil water retention curve, was assessed: the soil water content and the soil water potential (matric suction). The probes MPS-2 [18] and an EC-5 [19] were used (Figure 1), both connected to an Em-50 [20] data logger (manufactured by Decagon Device Inc./ Metter).

The EC-5 determines volumetric water content (VWC) by measuring the dielectric constant / relative electric permittivity of the media using capacitance and frequency domain technology. According to the operator's manual (Decagon, 2014) [19], the $70 \mathrm{MHz}$ frequency minimizes salinity and textural effects, allowing accurate measurements of all soils and soilless media. It is manufactured with factory calibration for mineral soils, potting soils, rockwool, and perlite.

About the probe's range, the Decagon's operator manual emphasizes that higher measurement frequency allows the EC-5 to measure VWC from 0 to $100 \%$ (VWC of saturated soils is generally 35 to $60 \%$ depending on the soil), and the accuracy might reach $1 \%$ for calibrated soils. However, authors like Veldkamp \& O'Brien (2000) [21], Choi et al., (2015) [22], and Bore et al., (2015) [23] highlight to increase data accuracy, the equipment must be calibrated.

The MPS-2 acquires values of the matric potential of soils by measuring the dielectric permittivity of a solid matrix (porous ceramic discs). This is possible because the dielectric constant or the relative permittivity of air, the solid ceramic, and water are different $(1,5$, and 80 respectively). In this way, the results from the porous ceramic discs depends on the amount of water present in the ceramic disc pore spaces. Further, the equipment calibration is not affected by the soil type because the sensors only measure the water potential of the ceramic discs in equilibrium with the soil water content (Decagon, 2004).
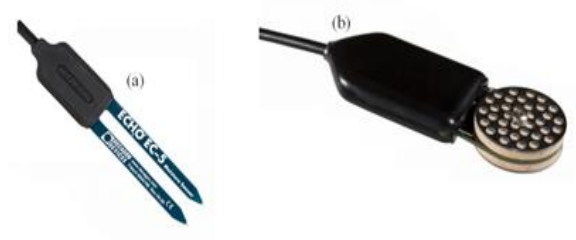

Fig. 1. EC-5 (a) and MPS-2 (b) Metter/Decagons.

Although it is considered a simple theory, reliable assays are not easy to be obtained, needing attention and care during the procedures. Dielectric measurements of soils require high precision and are time consuming 
because of the number of factors that affect soil dielectric behavior. In this way, Cihlar \& Ulaby (1976) [24] point out that a dielectric constant depends on moisture (Figure 2).

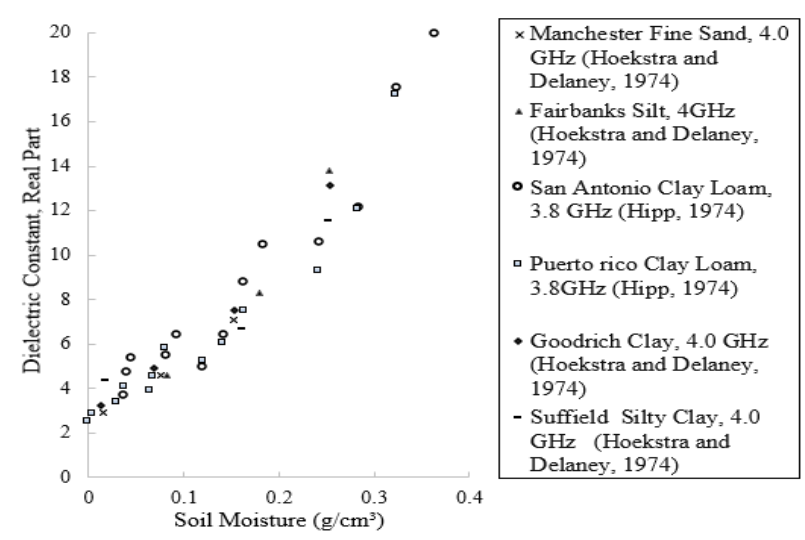

Fig. 2. Dielectric constant and its soil moisture dependence (Adapted from Cihlar \& Ulaby, 1976 [24]).

\subsection{Bulk Density test}

Considering that the current paper aims to analyze just one material and the frequency will be held constant, the analysis relies on the moisture and bulk density to understanding their influence on the EC-5 probe measured values. It is important to highlight that the MPS-2 was not tested in this procedure to protect the ceramic plates.

The tests were originally performed by field volumetric rings sampling (Kopecky) and laboratory Bulk density determination, relating the mass of water and solids (considered as the theoretical value).

Afterwards, the field Bulk density was replicated in the lab by two methodologies: compaction, conducted with the Normal Proctor (Figure 3-a), and a hydraulic compaction method, based on static compression (Figure 3-b). These procedures were performed because it is important to keep the integrity of the probes and it was not clear the Proctor strikes can guarantee it.

Thereafter, the Proctor compaction was performed using 3 layers compaction steps. During the layer's constitution, 24 strikes were disposed in a radial distribution and, to protect the probe, the central area was not reached by the standard socket.
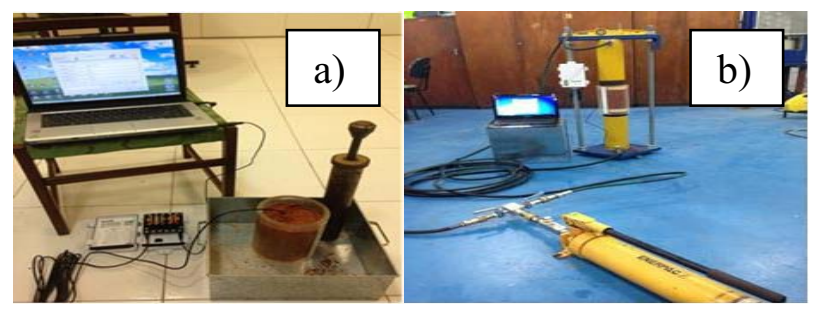
tests (b)

Fig. 3. Normal Proctor (a) and double ring compaction

The equipment developed consists of two hydraulic 30 tons actuators, manufactured by Enerpac, placed in opposite directions. The setup has a reaction structure and one hollow acrylic cylinder (diameter $=18 \mathrm{~cm}$; height $=30 \mathrm{~cm}$ ), where two concave polyethylene plates (top and base) drive the soils particles from the boundary to the sensor contact in the central sample area.

The tests were performed with the same compaction energy on the top and base, keeping the mass constant and varying the cylinder's volume (Figure $4 \mathrm{a}-\mathrm{c}$ ). As such, the natural Bulk density of the material was determined by volumetric measures of the cylinder.

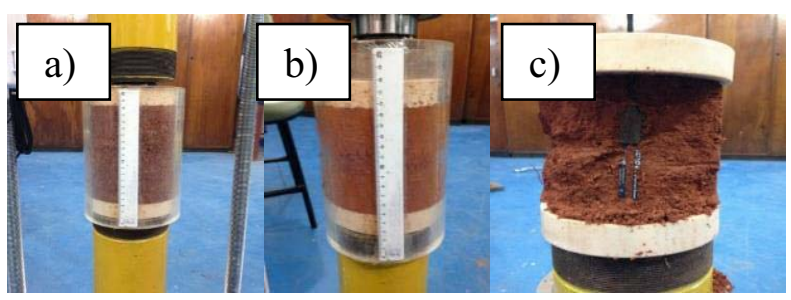

Fig. 4. a-c: Double ring compaction.

\subsection{Range of measurements - Ec-5/MPS-2}

Regarding the MPS-2 probes, a range of measurements were tested. The test setup consisted of two cylindrical samples in which the MPS-2 and the EC-5 probes were inserted in a saturated soil sample. A drying monitoring procedure was conducted for 7 days to observe the VWC and MP behaviors (Figure 5).

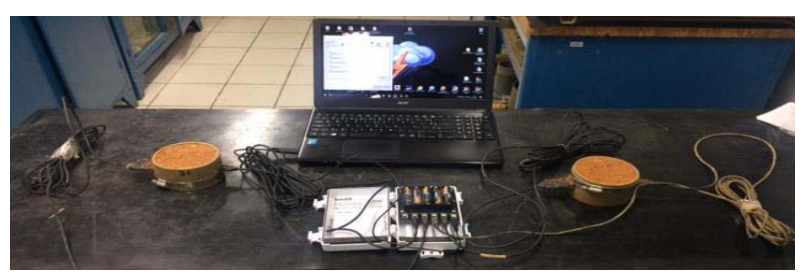

Fig. 5. Drying monitoring procedure.

\subsection{Installation procedures}

After concluding the laboratory procedures, a field installation campaign began to evaluate the procedures in a $25 \mathrm{~cm}$ deep borehole. Three distinct installation procedures were performed: driving the rod directly into the soil, with mud support (inside an auger hole), and with a hardened steel gauge (Figure 6 a-c). Here it is important to emphasize that the installation area was uncovered and that the soil was exposed to sunlight all day long.

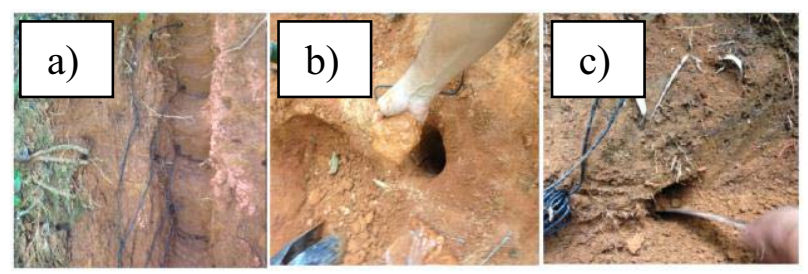

Fig. 6. a-c - Different installation procedures: driving the rod directly into the soil (a), with mud support (b), and with a hardened steel gauge (c). 


\subsection{D-Microtomography tests}

In addition, a 3D - Microtomography in a GE (phoenix v|tome $\mid \mathrm{x}$ m) [25] X-ray microfocus CT system was performed at the Nuclear Instrumentation Laboratory (LIN - UFRJ). The equipment is constituted by a dual $\mathrm{X}$-ray tube that is capable of obtaining powerful images to analyze the internal structure of soils and the probeground interaction (figure 7).

The test was performed with cylindrical soil samples $(15 \mathrm{~cm}$ diameter and $25 \mathrm{~cm}$ height) from each one of the E-5 field installation procedures (driving the rod directly into the soil, with mud support and with a hardened steel gauge). For the MPS-2, since the installation procedure required a borehole covered by mud, the image acquiring was performed with just one sample.

\section{Results}

\subsection{Laboratory Soil Water Retention Curve}

The laboratory soil water retention curve was determined by the filter paper method and fitted by Durner's (1994) [15] mathematic adjustment. It presented a bimodal geometry (Figure 7), which, according to Camapum de Carvalho (2004) [26], is related to tropical soils, to the pore structure and to discontinuous grain size distribution, once iron and aluminum oxi-hydroxes cements connect the soil aggregates.

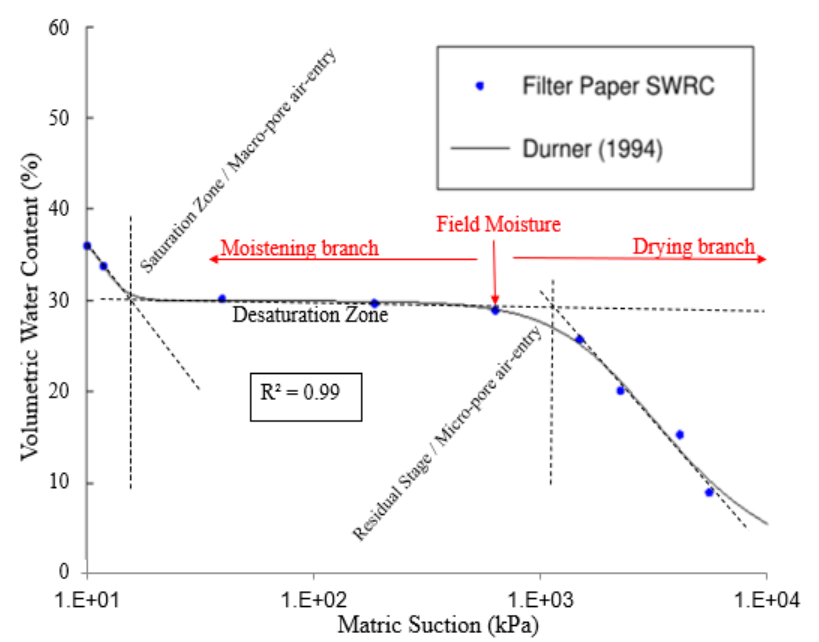

Fig. 7. Filter paper laboratory soil water retention curve.

\subsection{Field monitoring}

The field monitoring revealed the accordance of periods that occurred changes in volumetric water content and matric suction. The responses of sensors were close each other and with the increase of VWC (\%), the matric suction also increased (Figure 8)

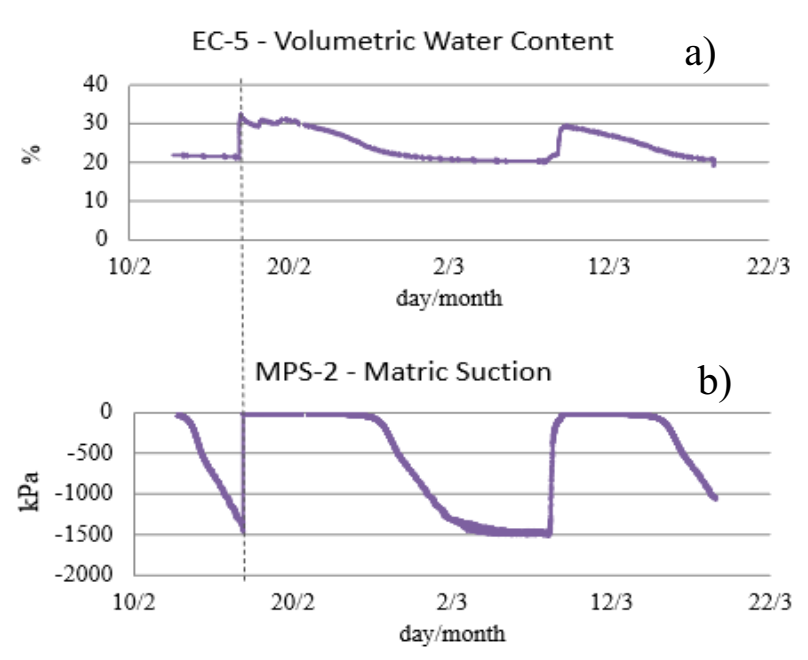

Fig. 7. Field monitoring - Volumetric Water Content (a), Matric Suction (b)

\subsection{Bulk Density test}

The Bulk density correlation tests presented a strong dependence on the EC-5 volumetric water content data. The compaction results (Table 3) showed that both methodologies (Proctor and double ring) reported an increase in EC-5 VWC values with an increase in soil specific mass. Further, it is noteworthy to highlight that the developed system produced a homogenous soil distribution, providing reliable results since the difference between the compaction methods and volumetric ring method (Kopecky) was small. Thus, it should be used for calibration tests since avoid Proctor strikes is recommended for probe's protection.

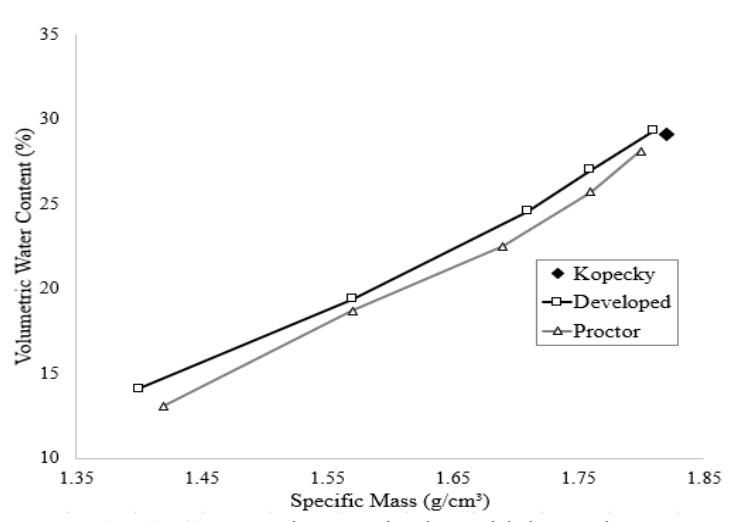

Fig. 9. Compaction methods and lab results.

As emphasized previously, about the necessity of a good soil-rod contact, figure 9 points out that a high Bulk density produces higher WVC outputted by the FDR EC-5, confirming that the soil-rod contact is an important subject and must be considered.

\subsection{Range of measurements - Ec-5/MPS-2}

Concerning the range test, Figure 10 depicts the geometric accordance between the matric potential probe values in comparison with the laboratory filter paper SWRC. However, it indicates a remarkable difference in 
volumetric water content EC-5 probe values, pointing out the calibration necessity of this probe for the tested soil.

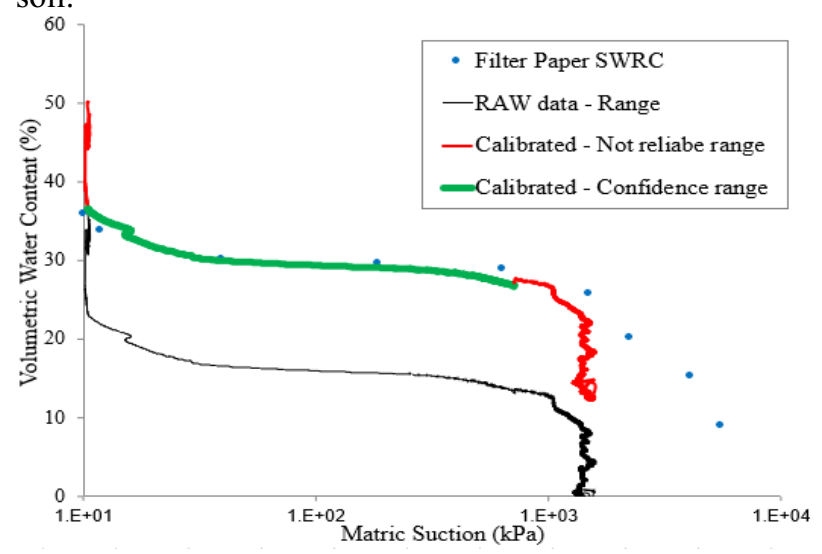

Fig. 10. Geometric accordance of field and laboratory data.

\subsection{Installation procedures}

The installation procedures were tested, and the results enhanced a similar geometry for all the field monitoring soil water retention curves and the laboratory procedure (Figure $11 \mathrm{a}$ and b). Comparing the installation procedures, driving the probe directly into the soil presented a lower calibration need since the values were lesser discrepant.

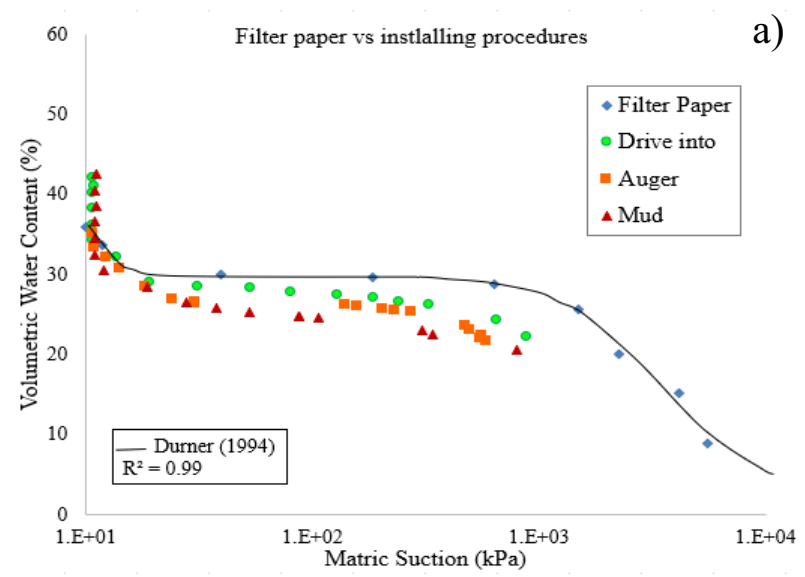

b)

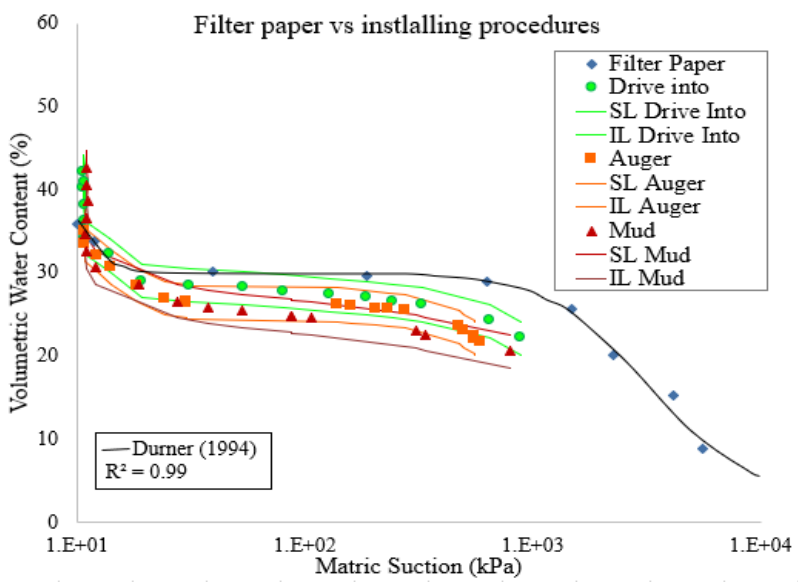

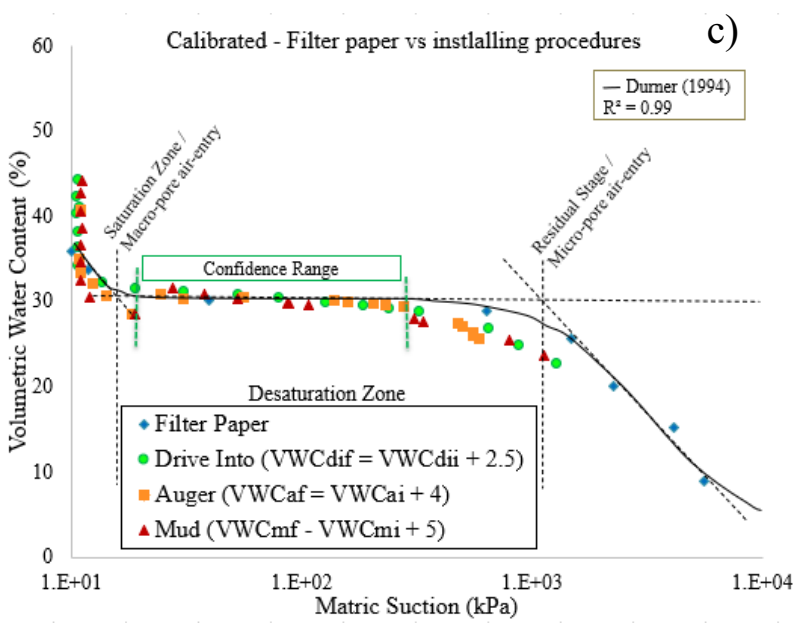

Fig. 11. Comparing installing equipment technics and lab values. a) RAW. b) Accuracy - RAW data and superior limits (SL) and inferior limits (IL) +- 2\% (indicated by the operator's manual ${ }^{19}$ ); c) Calibrated.

\subsection{D-Microtomography tests}

In addition, the samples for each installation procedure were submitted to microtomography imaging in order to visualize the internal structure of the soil and its contacts with the probes. To perform this analysis, samples with $15 \mathrm{~cm}$ of diameter and $30 \mathrm{~cm}$ of height were submited to 3D microtomography in a 741 image layers-rendering (Figure 12).

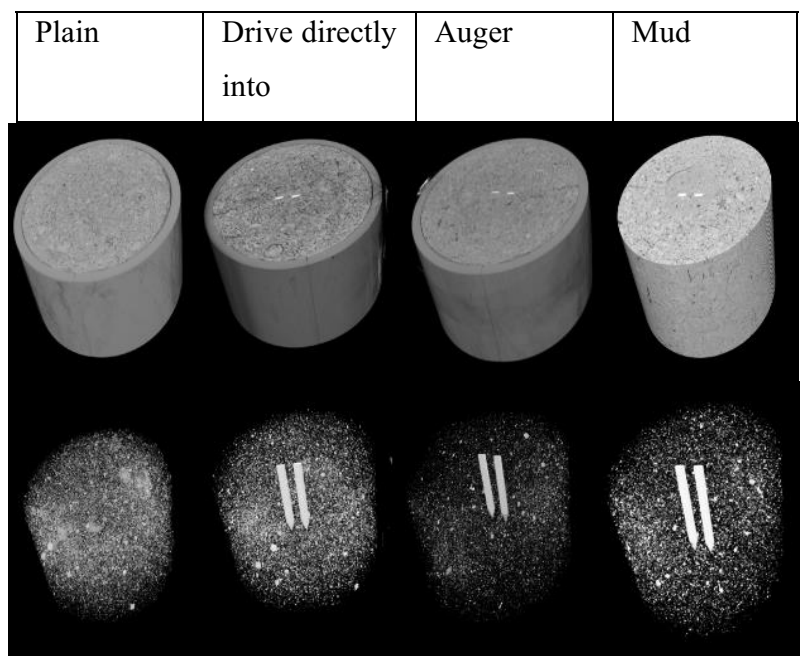

Fig. 12. Microtomography images - rendering the first 10 $\mathrm{cm}$ height.

The values were analyzed by two different focuses: one comprising the whole soil sample and another comprising of a small cylinder in the core area of the sample, closer to the probes. The results are displayed in the Table 4, and reveal an increase of object surface density in the core (exact point of probe installations); a reduction of closed pores, except for mud in the core; a reduction of closed pores, except for drive-in in the total area; an increase of opened porosity for drive-in in the total area; an increase of the core opened porosity in comparison with the full sample; an increase of pore connectivity in the core; a pore connectivity increase for 
drive in, and a pore connectivity decrease for the other techniques (comparing with the plain sample).

With an imaging resolution of $75 \mu \mathrm{m}$ for the whole cylinder and the core cylinder, an increase in closed porosity values for the mud procedure was observed. In addition, the total porosity presented the same pattern as the open porosity.

For the qualitative analysis, the figure 13 shows the top and transversal cut-off. Due to this is possible to notice the soil structure internal changes. Further, the images depict the same area of the samples revealing new voids caused by the mud injection. In addition, some cracks in the contact between the soil and the plastic ring were revealed, suggesting the occurrence of sampling problems.

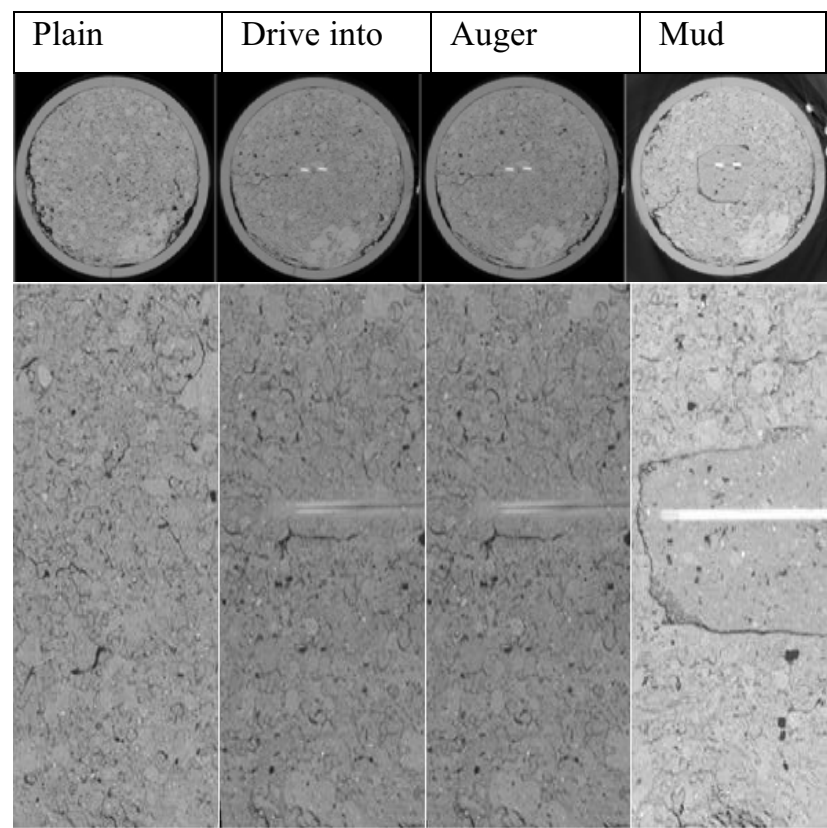

Fig. 13. Tomography images. Interaction between the probe and the ground.

Referring to the mud injection installation procedure, it is important to emphasize that the contact between the mud and the undisturbed soil presented a void disruption, suggesting that it was responsible for the higher discrepancy with the filter paper method.

Evaluating the drive in and the auger procedures, it was not possible to observe differences between the techniques in the figure 12 and 13. Because of this, another tomography routine was performed, with $3,8 \mathrm{~cm}$ of diameter and 7,6 cm of height, in order to obtain a higher resolution. Then it was possible to analyze the ground rod contact and comprehend the distinct field soil water retention curves.

The new images (Figure 14), presented some differences between the procedures, suggesting that the auger caused enlargements in some areas of the auger borehole. The divergence between the auger and drive in installation procedures is justified because the air, water and the solid matrix have different electrical conductivities.
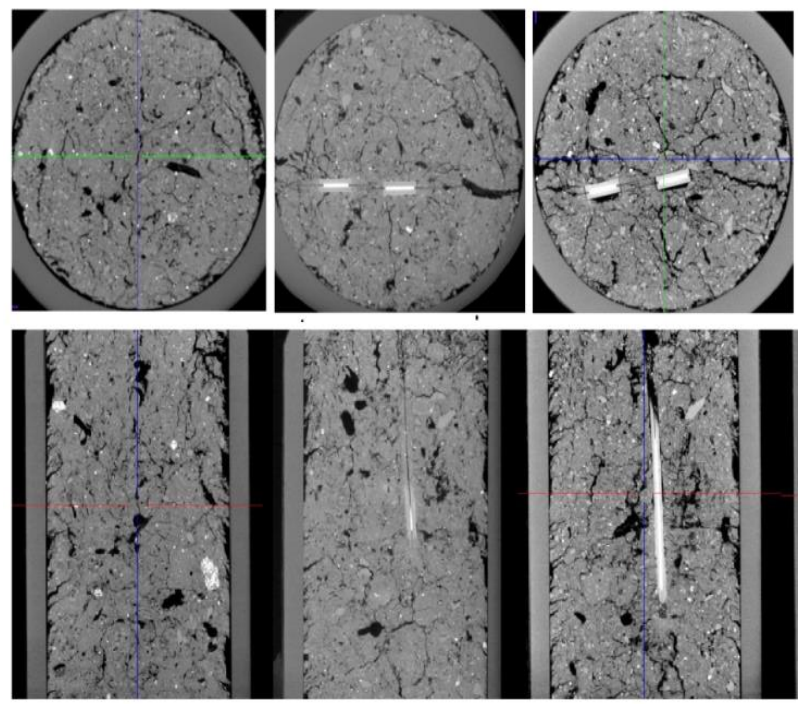

Fig. 14. Higher resolution microtomography images.

For the MPS-2, a 3D-microtomography was also performed to evaluate its installation effects. In this way, the figure 15 reveals some voids in the contact with the porous stone, suggesting it can cause some anomalous results.

Furthermore, the images emphasized high artefacts (noise) in the image rendering which was probably caused by the probe's metal body.

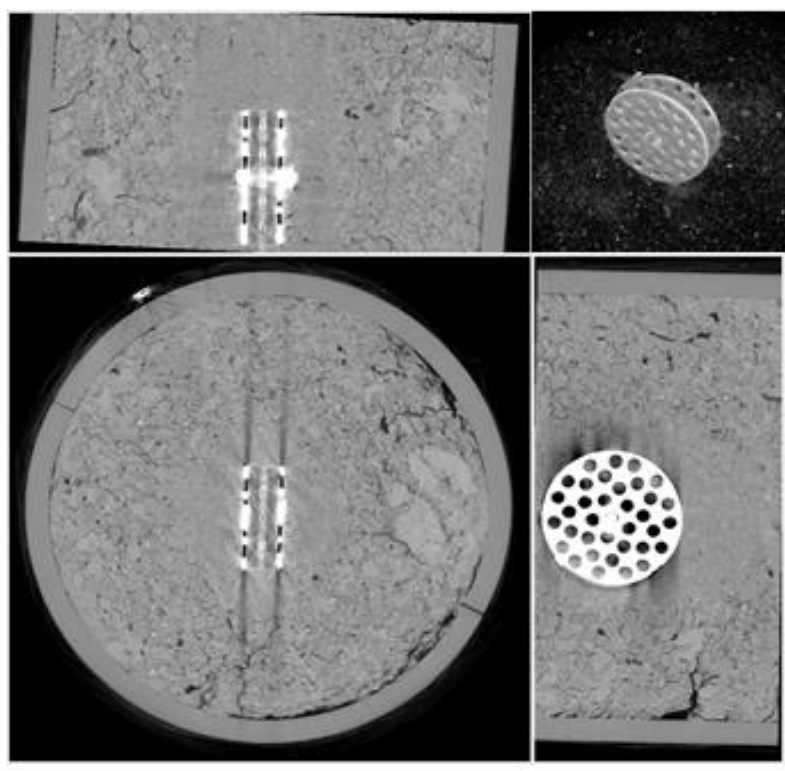

Fig. 15. MPS-2 tomography images. 
Table. 4. 3D-Microtomography - pore calculations.

\begin{tabular}{c|c|c|c|c|c|c|c|c|c}
\hline & & \multicolumn{4}{|c|}{ Full Sample } & \multicolumn{4}{c}{ Core } \\
\cline { 2 - 9 } Description & Unit & Plain & Drive into & Auger & Mud & Plain & Drive into & \multicolumn{1}{c}{ Auger } & Mud \\
\hline Total surface & $\mathrm{mm}^{2}$ & 37236.87 & 37236.87 & 37236.87 & 37236.87 & 9882.5 & 9882.5 & 9882.5 & 9882.5 \\
Object surface & $\mathrm{mm}^{2}$ & 364741.2 & 440917 & 253546.4 & 265615 & 59361 & 67636 & 63726 & 33566 \\
Object surface density & $1 / \mathrm{mm}$ & 0.77 & 0.94 & 0.54 & 0.56 & 0.92 & 1.05 & 0.99 & 0.52 \\
Volume of closed pores & $\mathrm{mm}^{3}$ & 3840 & 3417 & 5189 & 5367 & 411 & 450 & 463 & 842 \\
Surface of closed pores & $\mathrm{mm}^{2}$ & 77204 & 72872 & 96222 & 95222 & 8532 & 9385 & 9567 & 10500 \\
Closed porosity & $\%$ & 1.12 & 1.02 & 1.46 & 1.53 & 0.90 & 1.00 & 1.02 & 1.78 \\
Volume of open pore space & $\mathrm{mm}$ & 126361 & 133441 & 115305 & 117486 & 18787 & 19506 & 19106 & 16997 \\
Open porosity & $\%$ & 26.93 & 28.45 & 24.58 & 25.04 & 29.18 & 30.30 & 29.68 & 26.40 \\
Total volume of pore space & $\mathrm{mm}^{3}$ & 130201 & 136858 & 120494 & 122854 & 19199 & 19956 & 19569 & 17839 \\
Total porosity & $\%$ & 27.76 & 29.17 & 25.69 & 26.19 & 29.82 & 31.00 & 30.40 & 27.71 \\
Pore connectivity density & $1 / \mathrm{mm}^{3}$ & 0.00007 & 0.00012 & 0.00004 & 0.00005 & 0.00009 & 0.00015 & 0.00013 & 0.00006 \\
\hline
\end{tabular}

\section{Final considerations}

This paper confirmed that the EC-5, manufactured by Decagon Devices Inc., is strongly dependent on the material's Bulk density, and because of this, when the equipment is submitted to an installation procedure, it can produce unreliable data.

This sensor is extremely sensitive to installation techniques, requiring field calibration for different techniques in each installation point. Because of this, the tested procedures, (direct installing, auger and mud) revealed the same characteristics and underestimated the water content by $2.5 \%, 4 \%$ and $5 \%$, respectively.

The tomography images depicted that the use of the auger to install the probes in hard soils can cause cracks and void openings in the probe-soil contact. It underestimated the measured values of volumetric water content. The same behavior occurred for the mud-based installation. Due to structural change, the electrical permittivity altered, and the results were affected.

Although driving the rod directly into the soil had been the installation procedure that presented values closest to the laboratory results, it is important to emphasize that the brittle rod cannot be used for hard soils because it can cause damage to the sensor and wrong VWC values.

To produce a reliable field SWRC, the MPS- 2 does not need to be calibrated because the obtained values were well-fitted to the filter paper soil water retention curve. In this way, the key elements to achieve accurate data production are to perform a field calibration and to conduct a careful installation procedure of the EC-5 probes.

Finally, this research is fully applied to field monitoring procedures and can be used in several situations related to slope stability, foundations, erosion control, and further. As a suggestion, we expect and recommend improving the calibration for different soils and depths.
Acknowledgments: This research was financed by the Coordenação de Aperfeiçoamento de Pessoal de Nível Superior (Capes), Conselho Nacional de Desenvolvimento Científico e Tecnológico (CNPq), and Fundação Carlos Chagas Filho de Amparo à Pesquisa do Estado do Rio de Janeiro (FAPERJ).

\section{References}

1. D. G. Fredlund, N. R. Morgenstern, (1977). Sress State Variables for Unsaturated Soils. J. Geotech. Eng. Div. 103, 447-466

2. R. Gardner. (1937). A method of measuring the capillary tension of soil moisture over a wide moisture range. Soil Science vol. 43 277-283

3. L. Richards, L. Weaver. (1944). Moisture retention by some irrigated soils as related to soil moisture tension. J. Agric. Res. 69, 215-234

4. American Society for Testing and Materials. ASTM D5298-16 (2016). Standard Test Method for Measurement of Soil Potential (Suction) Using Filter Paper. doi:10.1520/D5298-16

5. American Society for Testing and Materials. ASTM C1699-09 (2015). Standard Test Method for Moisture Retention Curves of Porous Building Materials Using Pressure Plates. doi:10.1520/C1699-09R15

6. G. C. Topp, J. L. Davis. (1985). Measurement of Soil Water Content using Time-domain Reflectrometry (TDR): A Field Evaluation. Soil Sci. Soc. Am. J. 49, 19-24

7. K. T. Morgan, L. R. Parsons, T. Adair Wheaton, (2001). Comparison of laboratory- and fieldderived soil water retention curves for a fine sand soil using tensiometric, resistance and capacitance methods. Plant Soil 234, 153-157

8. A. G. Li, Z. Q. Yue, L. Tham, C. F. Lee, K. T. Law. (2005). Field-monitored variations of soil

\footnotetext{
$\bar{*}$ Corresponding author: thicarnavale@gmail.com
} 
moisture and matric suction in a saprolite slope. Can. Geotech. J. 42, 13-26

9. P. Osinski, D. Toll, E. Koda. (2016). Comparison of Soil Water Retention Curves for sandy clay, obtained using different laboratory testing methods. E3S Web Conf. 9, 7-11

10. Associação Brasileira de Normas Técnicas. NBR 7181. (2016). Análise granulométrica. 16 (2016)

11. Associação Brasileira de Normas Técnicas. NBR 6459. (1984). Solo - Determinação do Limite de Liquidez

12. Associação Brasileira de Normas Técnicas. NBR 7180 (1984). Solo - Determinação do Limite de Plasticidade

13. American Society for Testing and Materials. ASTM D854-14 (2014). Standard Test Methods for Specific Gravity of Soil Solids by Water Pycnometer. doi:10.1520/D0854-14

14. F. A. M. Marinho, O. M. Oliveira. (2006). The filter paper method revisited. Geotech. Test. J. 29, 250-258

15. W. Durner. (1994). Hydraulic conductivity estimation for soils with heterogeneous pore structure. Water Resour. Res. 30, 211-223

16. M. T. van Genuchten. (1980). A Closed-form Equation for Predicting the Hydraulic Conductivity of Unsaturated Soils. Soil Science Society of America Journal v. 44 892-898

17. Y. Mualem. (1976). A new model for predicting the hydraulic conduc. Water Resour. Res. 12, 513-522

18. Decagon Devices. (2017). MPS-2 and MPS-6 Dielectric Water Potential Sensors User 's Manual

19. Decagon Devices. (2010). Ec-5 Soil Moisture Sensors User 's Manual

20. Decagon Devices. (2018). EM50 Data Logger EM50 Data Logger User 's Manual

21. E. Veldkamp, J. O'Brien. (2000). Calibration of a Frequency Domain Reflectometry Sensor for Humid Tropical Soils of Volcanic Origin. Soil Sci. Soc. Am. J. - SSSAJ 64

22. E. Y. Choi, Y. H. Yoon, K. Y. Choi, Y. B. Lee. (2015). Environmentally sustainable production of tomato in a coir substrate hydroponic system using a frequency domain reflectometry sensor. Hortic. Environ. Biotechnol. 56, 167-177

23. T. Bore, N. Wagner, S. Delepine-Lesoille, F. Taillade, G. Six, F. Daout, D. Placko. (2015). 3D-FEM modeling of F/TDR sensors for clayrock water content measurement in combination with broadband dielectric spectroscopy. $S A S$ 2015 - 2015 IEEE Sensors Appl. Symp. Proc. 05
24. J. Cihlar, F. T. Ulaby. (1974). Dielectric Properties of Soils As a Function of Moisture Content. Remote Sens. Lab. $\mathbf{6 8}$

25. General Electric. (2014). Phoenix v|tome $\mid \mathrm{x}$ m Manual

26. J. Camapum de Carvalho. (2004). Propriedades e comportamento de solos tropicais nãosaturados. v. 2 597-616 